\title{
Parametric Architecture Today and Tomorrow
}

\section{Vytautas Baltus*, Laura Jankauskaite-Jureviciene, Tadas Zebrauskas}

Kaunas University of Technology, Faculty of Civil Engineering and Architecture, Studentu st. 48, LT-51367 Kaunas, Lithuania

*Corresponding author: vytautas.baltus@ktu.lt

$\Gamma$ crossef http://dx.doi.org/10.5755/j01.sace.25.2.21698
In the past fifteen years' avant-garde architectural practice has been developing in the field of parametric design at the phenomenal speed. This success can be attributed to the development of advanced computer software, previously used for animation and rendering. The parametric design method uses advanced computer scripts which transforms mathematic algorithms of relations between parameters into creations of complex geometries, which were almost impossible to produce and even imagine without it.

Intriguingly, there are examples of parametric design logics to find form and test structural tensions predating computers - i.e. structural tests of A. Gaudi (Fig. 1), F. Otto, L. Moretti.

Question remains will these mathematical equations inputted thru scripting language as algorithms will add additional value to the design, or traditional, intuitive way of designing still can be relevant enough in $21^{\text {st }}$ century. There are doubts that without deep intellectual background parametric design process can play for the play's sake with the shapes of objects, buildings and urban structures.

Keywords: parametric design, architecture, urban.

Parametric design has its roots in the digital animation techniques, but recently, with emerge of advanced design systems and scripting techniques, it became dominant style for avant-garde practice, which "sell" projects to clients as performative solutions based on what clients want their buildings to achieve - spectacular views, efficient circulation, improved working conditions, increased productivity, better use of resources and materials, more efficient communication. Architects do not talk about meaning, symbolism, metaphors, or even aesthetics. They know exactly what clients want and work with software, diagrams, parameters and spreadsheets. They never can tell what a building will look like until they consult every member on their team and run their designs through numerous variations before a particular version appears, based on allowing the data to emerge into a particular form. And the final form gets chosen out of numerous others that look only slightly different. These design methods follow a certain formulaic pattern of creating buildings based on calculation or programming rather than inspiration.

So it is hard to expect masterpieces like Chappelle Notre-Dame-du-Haut de Ronchamp (Fig. 2) or Yoyogi National Gymnasium, that were done as artistic and intuitive work that required a mixture of intuition, mathematics and geometry. There is less place for emotional architecture. Architects are looking for reasons for every curve and spike. They seem afraid of being accused as "artistic" or even "wasteful" (Belogolovsky, 2015).

\section{Introduction}

JSACE 2/25

\author{
Parametric \\ Architecture Today \\ and Tomorrow \\ Received \\ 2018/10/01 \\ Accepted after \\ revision \\ $2019 / 01 / 12$
}


Discussion

\author{
Fig. 1 \\ Structural test of \\ Sagrada Familia \\ by A. Gaudi
}

Fig. 2

Chappelle NotreDame-du-Haut de Ronchamp by Le Corbusier
The fascination with technology is a way of introducing new formal vocabulary that is going to explore certain spatial configurations that our mind has difficulty imagining. Parametric design encapsulates superior capacity to articulate programmatic complexity and our effort of putting it all into algorithms and scripts instead of hand sketch are compensated by adding superior intelligence layer, rewarding us with exploration of generated surprising discoveries of unimagined design outcomes. In the future architects, or even clients will explore the whole range of possible solutions that the variability of the initial parameters allows.

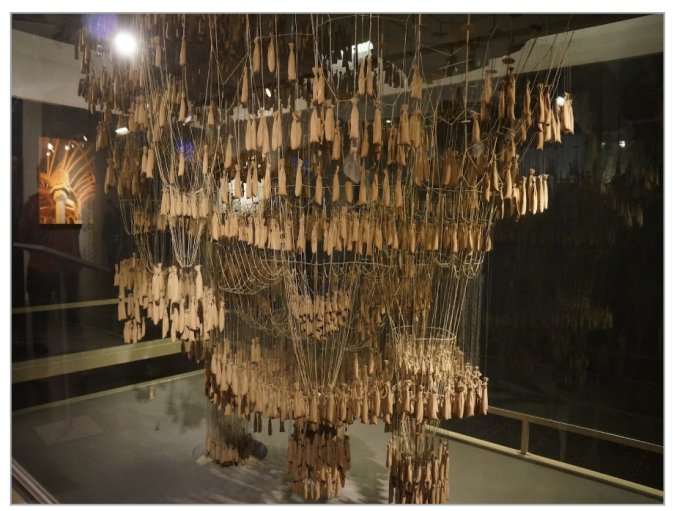

Not everyone, however, is enamoured by computer design or the promise of parametric systems. Christopher Alexander, even in 1965, warned that architects might "fatally distort the nature of design by restating design problems solely for the purpose of using the computer." (Schumacher, 2009) He did not believe that there were design problems - environmental or architectural - so complex that they require a computer to solve, and he was not convinced that architects would not oversimplify design complexity to meet the limited input and operational capacities of their computers. The computer could not keep pace with the facility of human intuition for inventing architectural forms and deriving design solutions for complex problems.

Mathematical parametric and algorithmic procedures most often have proven far too rigid to productively engage the complex cultural, societal, economic and political projects facing architects today. Designing buildings and cities using parametric and scripting design tools may often appear visually stunning, but for the most part these designs tend to incorporate far too many blind assumptions to be able to respond with nuance to real world situations. Moving away from delimiting input techniques derived building forms and urban typologies, but the design vanguard has begun focusing more on the performative and affective qualities of architecture.

The Parametric design generates geometry from the definition of a family of initial parameters and the design of formal relations they keep with each other. Algorithms are used as a primary design methodology which employs computer scripting, thus, excluding initial and intuitive design idea, hand sketch of final geometry at first (Fig. 3).

Nevertheless, advocates of parametric design argue that such an innovative adaptation of architecture and urbanism retools and adapts the discipline to the demands of the socio-economic era. Parametric design techniques - employment of animation, simulation and form-finding tools, as well as parametric modelling and scripting - addresses societal demand and inspires a new collective movement with radically new ambitions and values. Thus, we are confronted with a new style rather than just with a set of techniques. Above aesthetic recognisability it transforms into a sense of epochal phenomenon.

Modernism was accused of single style dullness, while parametric design allows continuous differentiation, versioning and customisation. Virtuosity and refinement, facilitated by the develop- 
ment of parametric design tools and scripts allow precise formulation and execution of intricate correlations between elements and subsystems. Shared concepts, computational techniques, formal repertoires and tectonic logics that characterise this work are crystallising into a solid new paradigm of architecture.

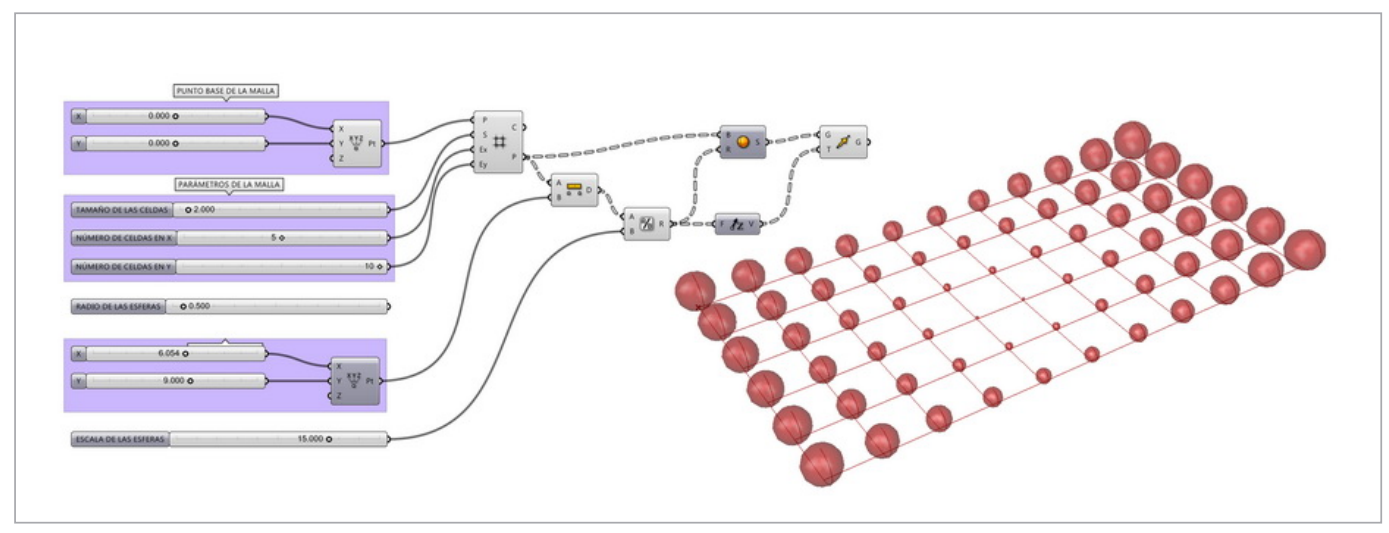

Creative exploitation of parametric design systems articulates increasingly complex social processes. Aesthetically it is the elegance of ordered complexity and the sense of seamless fluidity, akin to natural systems. Architectural progression of styles proceeds together with innovations of collective endeavour, cumulative advancements in technology. Each style has its core of principles and a characteristic way of tackling design tasks. The parametric design programme consists of methodological rules: some tell us what paths to avoid and other what pats to pursue. It formulates strictures that prevent relapse into old patterns and preferred techniques as guiding principles that allow to work forward.

The defining principles of parametric design style are reflected in taboos and dogmas of contemporary avant-garde design culture: avoiding rigid geometric primitives like squares, triangles and circles, to avoid simple repetition of elements and consider all forms to be parametrically malleable, differentiate gradually, correlate systematically (Fig. 4).

Designer's realisation of unique formal and organisational opportunities are afforded by the continuous advancement of the sophisticated computational geometry design processes. Scripting and parametric modelling are essential to compete today within avant-garde scene and mastering and advancing in these techniques is a must for an architect. However, the advancements of techniques should go hand in hand with formulation of further ambitions and goals, such as rationality of parametric design, which, still in it's implementational infancy, might involve accentuation, figuration and responsiveness able to produce modulations of morphologies and powerful architectural or urban effects facilitating field orientation. Although no unique optimal solution exists and each computation is different, characteristic patterns emerge in different regions of the parametric space.

Le Corbusier's theoretical statement on urbanism starts with eulogy of the straight line and the right angle as means by which man conquers nature. Contrast of man's way with the donkey's way is depicted in The City of tomorrow as follows: "Man walks in a straight line because he has a
Fig. 3

Example of algorithm design method

Fig. 4

Zaha Hadid's architects parametric design example for urban structure 
goal and knows where he is going; he has made up his mind to reach some particular place and he goes straight to it. The donkey meanders along, meditates a little in his scatter-brained and distracted fashion, he zig-zags in order to avoid larger stones, or to ease to climb, or to gain a little shade; he takes the line of least resistance." (Le Corbusier, 1925) Le Corbusier admires urban order of Romans and rejects sentimental attachment to the picturesque irregularity of medieval cities: "The curve is ruinous, difficult and dangerous; it is a paralysing thing." Le Corbusier insists that "the house, the street, the town should be ordered; if they are not ordered, they oppose themselves to us." Le Corbusier's limitation is not his insistence upon order, but his limited concept of order in terms of classical geometry. Phenomena like the "donkey's path" and the urban patterns resulting from unplanned settlement processes can now be analysed and appreciated in terms of their underlying logic and rationality.

Le Corbusier realised that although "nature presents itself to us as a chaos, the spirit which animates Nature is a spirit of order." However, understanding of nature's order was limited by the science of his day. Today we can reveal the complex order of those apparently chaotic patterns by means of simulating them.

Modernism was founded on the concept of universal space. Parametric design differentiates fields. There are no platonic, discrete figures or zones with sharp outlines. There are no more landmarks to hold on, no axis to follow and no more boundaries to cross.

Parametric design concept of deep relations also leads to multiple adaptations that trigger ordered complexity and replaces monotony of planned developments or disorienting visual chaos. It further intensifies correlations, involving systematic modulation of tectonic features. Parametric design is able to further coordinate pragmatic concerns and articulate them with all their rich differences and relevant associations.

The overall idea of Parametric Design holds an important strategic potential for creating a positive impact on the environment of architectural and especially urban design field, due to its important practical, economical, or later even maybe measured ecological dimension that can be added as one of the parameters in the algorithm.

Only in last decade parametric modelling gone from being a mathematical trick employed by Gaudi, Otto, Sutherland and some engineers to being a regular part of architectural practice. In architecture parametric modelling is complemented by an utilitarian dogma for exploring all possibilities offered by such model. This exploration is facilitated both through modification of model parameters and their relationships. In present day parametric modelling is no longer the exclusive domain of overtly parametric tools, but parametric equations quietly drive many BIM tools, they manifest in textural script languages and are exposed by graph-based visual scripting interfaces. Parametric modelling is present, in some form, on most contemporary architectural projects and probably will be a must for future profession.

We have all at some point used a spreadsheet to solve a specific mathematical problem. Starting with intentionally chosen values, and under certain rules that we have imposed on the system when setting it up, we are able to instantly obtain very complex results, which also, can be immediately recalculated by simply tweaking the original parameters. But, what if we could mimic this process with geometry?

The ground of parametric design is the generation of geometry from the definition of a family of initial parameters and the design of the formal relations they keep with each other. It is about the use of variables and algorithms to generate a hierarchy of mathematical and geometric relations that allow you to generate a certain design, but to explore the whole range of possible solutions that the variability of the initial parameters may allow. 
The benefits of this process are immediate. It is a huge leap in the quality of our process, since we are not bound by our tools anymore; now it will be us who design our own tools. On the other hand, parametric design is fundamental when minimising the effort needed to create and test design variants. Generating an automated process eliminates tedious repetitive tasks, the need for complicated calculations on the fly, the possibility of human error, and generates huge shifts in the outcomes with slight variations of the original parameters. Parametric thinking introduces the shift in the mindset between the search for an specific static and defined formal solution, and the design of the specific stages and factors used to achieve it. It is the use of algorithms and advanced computational techniques not for the sake of drawing shapes, but creating formal possibilities. It is not about producing a solution, but the family of possible outcomes. It is the shift from using CAD software as a representation tool, to do it as a design tool. It is, altogether, the new paradigm.

Glancey J. 2017. What's so great about the Eiffel tower? London, Lawrence King Publishing, 140-141.

Belogolovsky V. 2015. Conversations with architects in the age of celebrity. Berlin, DOM publishers. 30-31.
Le Corbusier. 1929. Urbanisme. New York, Payson \& Clarke Ltd., 5-18.

Schumacher P. 2009. Parametric Patterns. Archit Design, 79: 28-41.https://doi.org/10.1002/ad.976

\section{References}

\section{About the \\ Authors}

VYTAUTAS

BALTUS

\section{Lecturer}

Kaunas University of Technology, Faculty of Civil Engineering and architecture

\section{Main research area}

Architectural design

\section{Address}

Studentu str. 48-309, LT-51367 Kaunas Tel. +370606 30306 E-mail:vytautas.baltus@ktu.lt

\section{LAURA JANKAUSKAITE- JUREVICIENE}

\section{Lecturer}

Kaunas University of Technology Faculty, of Civil Engineering and architecture

\section{Main research area}

Architectural design

\section{Address}

Studentu str. 48-309, LT-51367 Kaunas Tel. +370 68874418 E-mail: laura.jankauskaitejureviciene@ktu.lt
TADAS ZEBRAUSKAS

Lecturer

Kaunas University of Technology Faculty of Civil Engineering and architecture

\section{Main research area}

Architectural design

\section{Address}

Studentu str. 48-309, LT-51367 Kaunas

Tel. +370 61832820

E-mail: tadas.zebrauskas@ktu.lt 